Vol. 14, No. 2, May, 2021 ISSN: 2090-5890 \& 2735-3222

\title{
Comparison of The Flow Characteristics between Circular and Wedged Configurations in Internal Combustion Engine Chambers
}

\author{
Mr. Moustafa Moustafa Mohamed Ahmed Amer \\ Mechanical power engineering Dep., \\ Faculty of Engineering, \\ Mataria, Helwan University.
}

\section{Research Summary in English:}

Flow characteristics in internal combustion engine chambers of wedged and circular cross-sectional configurations were numerically investigated during intake stroke. The convex radius reduction effect on primary and secondary flow parameters was studied. Results indicated a pressure drop increase of $0.05 \%$, and swirl number and secondary vortex intensity reductions of $14.04 \%$ and $75.57 \%$ respectively compared to circular configuration. Further optimization is needed to increase compactness without sacrificing performance.

\begin{abstract}
In this paper, a numerical study was conducted to investigate the steady-state flow characteristics of the breathing stroke in internal combustion engine chambers with wedged and circular cross-sectional configurations. The effect of reducing the convex radius on the primary flow was studied, considering total pressure drop. Secondary flow characteristics were also analyzed using parameters such as; swirl number and secondary vortex intensity. The pressure drop ratio of the wedged configuration to the circular configuration was found to be less than 1.05 at crank shaft angular velocity of $3000 \mathrm{rpm}$, which is comparable to the circular configuration values. On the other hand, the average values of secondary vortex intensity and swirl number of the wedged design were found to be $0.18 \mathrm{~s}^{-1}$ and 0.02 at the same operating conditions, which present a $14.04 \%$ and $75.57 \%$ reduction compared to the circular configuration, accounting for less mixing. The acquired data suggests that trying to optimize the combustion chamber design by lowering its total weight and volume has its drawbacks, which raises the need for innovative designs that can overcome these obstacles.
\end{abstract}

Keywords: WJ-BSL-EARSM model - Secondary flow - Non-circular cross-sections - Steady-state Intake stroke 
ملخص البحث باللغة العربية:

خصائص التدفق في الحالة المستقرة لغرف محرك احتراق داخلي ذات مقطاع دائرية و إبفينية الشكل خلال شوط

السحب. تمت دراسة أثر تقليل نصف القطر المحبب لتصميم الإسفين مقارنة بالتصميم الدائري على معاملات التدفق الأولية والثانوية

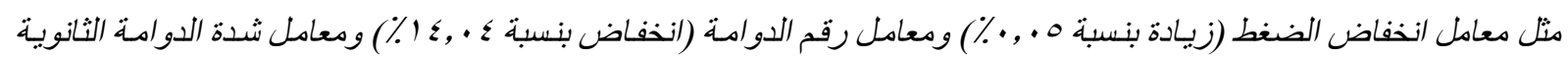
(انخفاض بنسبة O0,OV\%). وقد كثفت النتائج عن الحاجة إلى مزيد من الدراسة لتحسين غرف الاحتراق عن طريق خفض حهمها

الكلي.

transfer, combustion process, and air fuel mixing [8-10]. The performance relies on the designs of the cylinder head, inlet port and valve interacting with piston movement and cylinder walls $[6,10]$.

The flow conversion from laminar towards turbulent flow is identified by critical Reynolds number (Re_cr), that depends on flow characteristics, fluid properties, and the shape of the domain [11]. Qian et al. [12] investigated the impact of varying the inlet aperture diameter and the expansion ratio on $\mathrm{Re}_{\mathrm{er}}$ number for single fracture with abruptly changing apertures (SF-ACA). The results showed that for several studied configurations, the $\mathrm{Re}_{\mathrm{cr}}$ number values were below 50 .

Pressure drop through the combustion compartment, particularly across the valve and the intake port is of high significance in the engine performance [13]. Thobois et al. [14] modelled the intake stroke by a steady state flow of nitrogen across a sudden expansion pipe equipped with a valve. They revealed

\section{Introduction}

The main attribute to the worldwide power usage is the internal combustion engines (ICEs) [1,2]. Experiments along with computational fluid dynamics (CFD) are conducted to improve efficiency and reducing emissions and costs of ICEs [3]. Electrical engines would take a considerable time to replace ICEs. Doubts about time and capabilities are discussed if electrical engines would be a replicable of diesel engines used in ships and heavy machines. [4]. Internal combustion engine classification could be categorized into two main types. The first kind is reciprocating ICE and could be further classified based on cylinder alignments to in-line, V-shape, radial, opposed piston, and opposed cylinders configurations [5,6]. The other kind is piston-less rotary engines, which was studied by Wankel, Libralato, Szorenyi, and others [6,7].

The gas motion characteristics during the breathing stroke, especially turbulent characteristics and bulk motion are the dominant parameters of heat 
the investigated conditions, the optimal values of GVSTD angle, number, height, and length were $35^{\circ}, 3,0.7 \mathrm{R}_{\mathrm{IR}}$, and $3 \mathrm{R}_{\mathrm{IR}}$, respectively. $\mathrm{R}_{\mathrm{IR}}$ is specified as the intake runner radius. The optimal values made a rise in efficiency and decreases in brake specific fuel consumption (BSFC) and emissions.

The present study investigates a proposed combustion chamber configuration of wedged cross-section in order to get a more compact design. Impacts of operating and geometric parameters such as mass flow rate and cross-section besides the flow parameters such as total pressure drop, swirl number, and secondary vortex intensity were investigated. The final purpose of the current study is to assess the proposed configuration and conduct a comparison between the proposed and other conventional designs.

\section{Combustion Chamber Design}

In the present study, a proposed configuration of wedged combustion chambers arranged to be concentric at the sharp corner was considered for the sake of reducing the overall convex radius. A comparison between the proposed wedge design (WD) and the circular design (CD) was under investigation. Figure 1 (a) represents an isometric view of the WD, that the highest-pressure drop was mainly in the valve zone, then by the port, while the lowest-pressure drop was in the cylinder head region of the chamber. After top dead center (TDC), the pressure drop could be neglected.

Swirl is a significant parameter which characterizes the fluid flow rotation around the axis of the chamber axis. It is introduced by initially charging the fluid by an angular momentum. Swirl increases pressure drop to improve the combustion rate, flame propagation speed, and air-fuel mixing [15-19]. Arcoumanis et al. [20] discussed turbulent flow characteristics for a chamber geometry with and without swirl. Results exposed that swirl caused a decrease in the cyclic fluctuation and the integral scales of the mean flow velocity and turbulence. On the other hand, it was concluded that swirl leads to more homogeneous turbulence intensity.

Guide vane swirl and tumble device (GVSTD) is located in the intake manifold to generate more turbulence, mixing, and flow characteristics [21]. Biodiesel engines are usually supplied with this device because of the slow evaporation rate and the high viscosity characteristics of the biodiesel fuel [22]. Bari and Saad [22-25] conducted many researches to find the optimal design parameters of GVSTD. For 
same cross-sectional area for the purpose of comparison.

Hydraulic diameter is a design parameter, which could be defined as follows;

$$
\mathrm{D}=\frac{4 \mathrm{~A}}{\mathrm{P}}
$$

where $\mathrm{D}[\mathrm{m}]$ is the hydraulic diameter, $\mathrm{P}[\mathrm{m}]$ is the cross-sectional wetted perimeter and $A\left[\mathrm{~m}^{2}\right]$ is the crosssectional area.

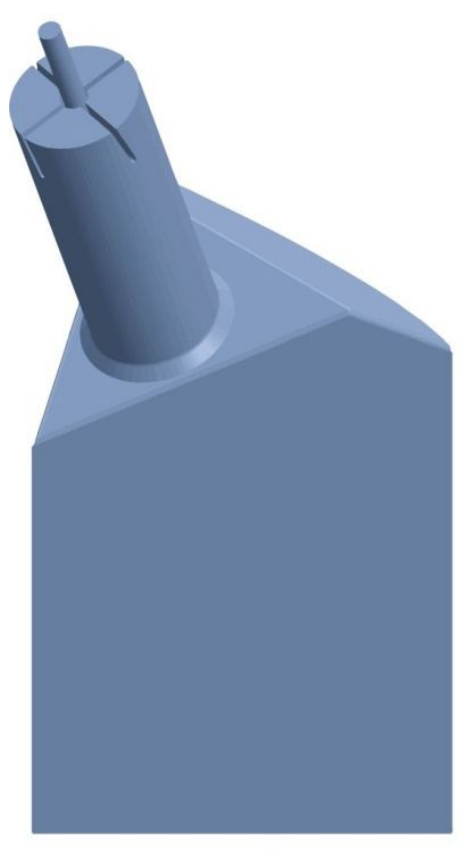

(a) while a detailed front view is represented in Figure 1 (b). One inlet valve of a valve lift of $7 \mathrm{~mm}$ is equipped in the combustion chamber intake manifold. Straight port with inclination is supplied with a GVSTD that is consisted of four guide vanes which is characterized by helical pitches of $400 \mathrm{~mm}$ for tumble and swirl generation. The center of gravity related to one half of the compartment is the chosen position of the port and geometry. Figure 2 (a) shows a cross-sectional view of $\mathrm{CD}$, whereas Figure 2 (b) represents a cross-sectional view of WD. The two designs have the
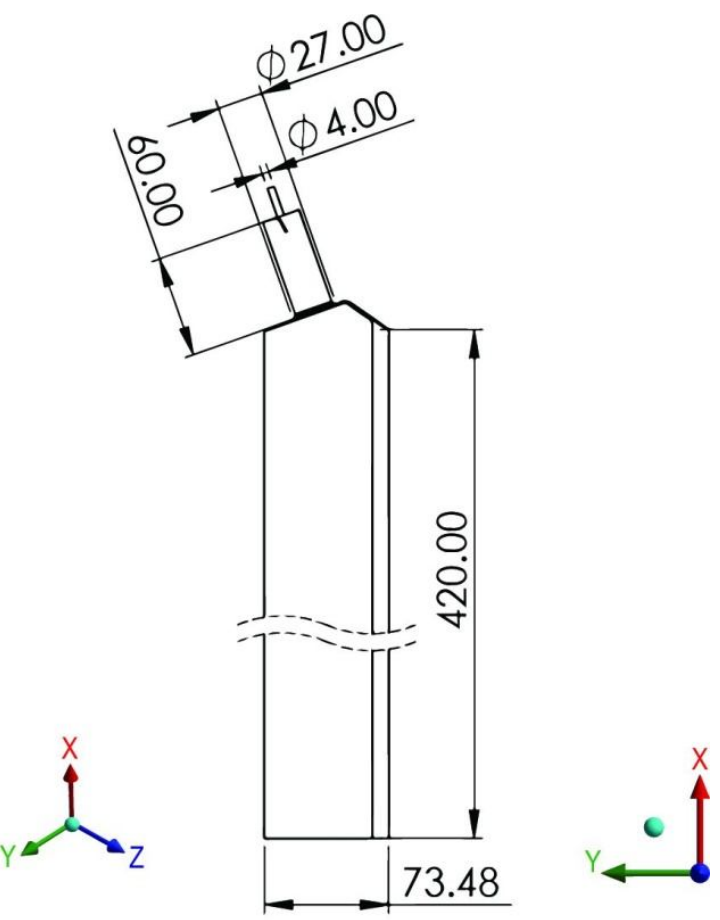

(b)

Figure 1 Details of WD (a) isometric view and (b) Detailed front view 


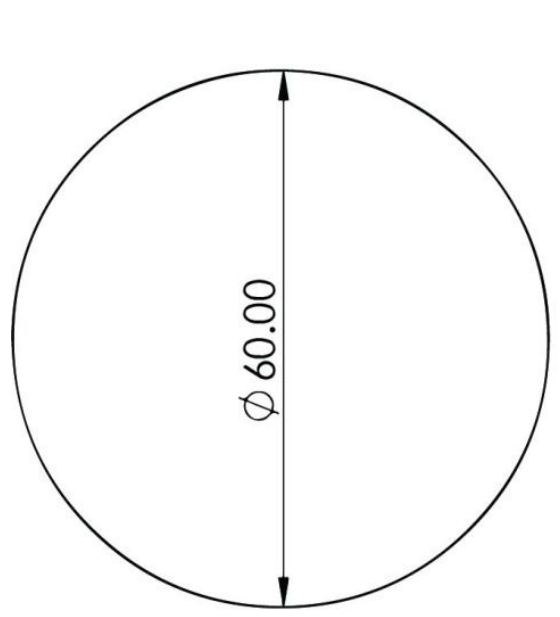

(a)

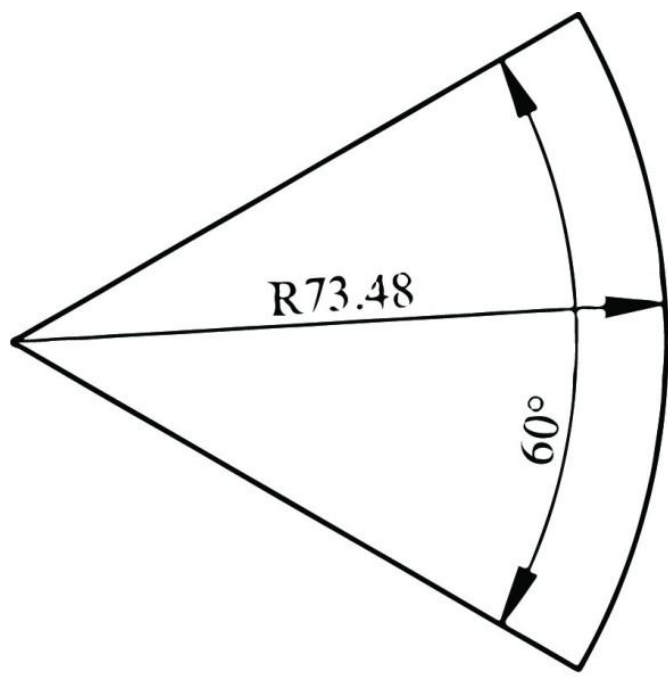

(b)

Figure 2 Cross-sectional view of (a) CD and (b) WD

\section{Modelling and Simulation}

The working fluid is air with a dynamic viscosity and a density of $1.7894 \times 10^{-05}$ Pa.s and $1.225 \frac{\mathrm{kg}}{\mathrm{m}^{3}}$, respectively.

The computational fluid dynamics (CFD) modelling has the following assumptions;

- Single component flow

- Steady flow

- 3-D fluid flow

- Isothermal flow

- No gravity effects

- Incompressible fluid

WJ-BSL-EARSM is the used model in the present work which depends on the explicit algebraic model of Reynolds stress done by Wallin and Johansson [26]. Reynolds stress transport equations [27-
29] are the basis of this model and it's extended by BSL $\mathrm{k}-\omega$ model [30] to get the secondary flow characteristics and the anisotropy of Reynolds stresses. A nonlinear relation is introduced among the mean strain-rate and vorticity tensors along with the Reynolds stresses.

The conservation equations of mass and momentum could be written as follows;

$\nabla \cdot \rho \vec{V}=0$

$\nabla \cdot(\rho \vec{V} \times \vec{V})=-\nabla p+\nabla \cdot\left[\mu\left(\nabla \vec{V}+\nabla \vec{V}^{T}\right)\right]$

where $\rho$ is the density, $\vec{v}\left[\frac{m}{s}\right]$ is the velocity vector, $\mathrm{p}[\mathrm{Pa}]$ is the pressure, $\mu$ [Pa.s] is the dynamic viscosity and $\overrightarrow{\mathrm{V}}^{\mathrm{T}}\left[\frac{\mathrm{m}}{\mathrm{s}}\right]$ is the velocity vector transpose.

The boundary conditions could be listed as follows; The four cross-sectional area at the guide vanes beginning have an 
inlet mass flow rate of a range of 3.5 to

$20.8 \mathrm{~g} / \mathrm{s}$ which correspond to a range of crankshaft angular velocity $\mathrm{N}=500: 3000 \mathrm{rpm}$. Zero-gauge pressure at the outlet and no-slip conditions at walls are the other boundary conditions.

\section{The combustion chamber performance} could be identified using the following

\section{parameters:}

\section{Total pressure drop}

The total pressure drop through the compartment is estimated by the following equation

$\Delta \mathrm{p}_{\text {tot }}=\mathrm{p}_{\text {tot }}-\mathrm{p}_{\text {in }}$ tout

where $\Delta \mathrm{p}_{\text {tot }}[\mathrm{Pa}]$ is the total pressure drop, $\mathrm{p}_{\text {tot }_{\text {in }}}[\mathrm{Pa}]$ is the total pressure at the inlet, and $\mathrm{p}_{\text {tot }}[\mathrm{Pa}]$ is the total pressure at the outlet.

\section{Swirl number}

The swirl number (S) is defined by the angular momentum axial flux $\mathbb{Z}\left(\mathrm{G}_{\mathrm{Q}}\right)$ divided by the axial momentum axial flux $\left(G_{x}\right)$ [19]

$$
\mathrm{S}=\frac{\mathrm{G}_{\theta}}{G_{\mathrm{x}}}=\frac{\int r w \overrightarrow{\mathrm{V}} \cdot \mathrm{d} \overrightarrow{\boldsymbol{A}}}{\overline{\mathrm{R}} \int \mathrm{u} \vec{V} \cdot \mathrm{d} \overrightarrow{\mathrm{A}}}
$$

where $r[m]$ is the radial space coordinate, ${ }^{\mathrm{w}}$ and $u\left[\frac{\mathrm{m}}{\mathrm{s}}\right]$ are the velocity components of the tangential and axial directions, respectively, and $\overline{\mathrm{R}}[\mathrm{m}]$ is the hydraulic radius.

\section{Absolute secondary vortex intensity}

The absolute secondary vortex intensity $\left(\mathrm{Jabs}_{\mathrm{a} s}^{\mathrm{n}}\left[\mathrm{s}^{-1}\right]\right)$ could be calculated by the absolute of the vorticity flux in the cross-sectional normal direction [31].

$$
\mathrm{J}_{\mathrm{abs}}^{n}=\frac{1}{\mathrm{~A}} \int\left|\omega^{\mathrm{n}}\right| \mathrm{dA}
$$

where $\omega^{\mathrm{n}}\left[\mathrm{s}^{-1}\right]$ is the vorticity in the cross-sectional normal direction.

The computational fluid flow model was constructed by the commercial package of the software of ANSYS Products 19.3. Unstructured mesh was constructed using ANSYS Meshing 19.3 software. The mesh was made for the domain discretization as presented in Figure 3. The mesh is a fine mesh to consider the effects of secondary flows and other fluid flow characteristics. Inflation layers are established to clearly identify the boundary layer features. The mesh size is refined at the valve and the guide vanes vicinities because of the rapid changes occurred in the flow and the sudden expansion.

The calculations were conducted by ANSYS Fluent 19.3 finite volume analysis software. Coupled algorithm scheme was the solution implementation technique. The spatial discretization established was least 
squares cell based for gradient, second order for pressure, and second order upwind for momentum, turbulent kinetic energy, and specific dissipation rate. The convergence criteria identified by maximum residuals of $10^{-5}$ for all the monitored parameters.

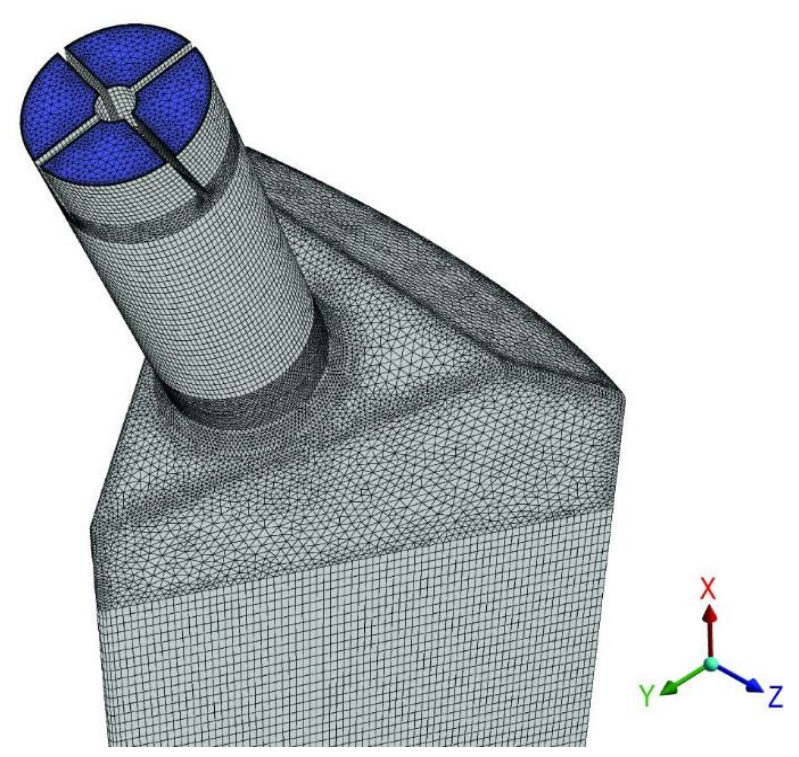

Figure 3 Isometric view of WD meshing

The mesh size was investigated to find the optimal lowest size, which gives results that are independent of the mesh size. Table 1 shows the mesh dependency test results depending on the percentage difference of mesh size error (PDMSE) of the monitored parameter. It's defined as the radial variation (the ratio of the radial space coordinate $(\mathrm{r})$ divided by the circular cross-sectional radius $(\mathrm{R})$ ) of the ratio of the axial velocity ( $\left.V_{\text {axial }}\right)$ over the bulk velocity ( $V_{\text {bulk }}$ ). $V_{\text {bulk }}$ is the ratio of the mass flow rate divided by the crosssectional area.

PDMSE $=\frac{\left|\mathrm{MP}_{\mathrm{SM}}-\mathrm{MP}_{2 \mathrm{M}}\right|}{\left|\mathrm{MP}_{2 \mathrm{M}}\right|} \times \mathbf{1 0 0} \%$

where $\mathrm{MP}_{S \mathrm{M}}$ is the monitored parameter of the selected mesh size and $\mathrm{MP}_{2 \mathrm{M}}$ is the monitored parameter of the 2M cell mesh size.

Results revealed that that mesh size of $1.5 \mathrm{M}$ cells is the optimal size, which gives a good agreement with $2 \mathrm{M}$ cells with maximum error of $1.96 \%$. 
Table 1 Mesh dependency study results

\begin{tabular}{|l|l|}
\hline Number of cells (cells) & Percentage difference of mesh size error [\%] \\
\hline $0.5 \mathrm{M}$ & 23.28 \\
\hline $1.0 \mathrm{M}$ & 6.68 \\
\hline $1.5 \mathrm{M}$ & 1.96 \\
\hline
\end{tabular}

The model was validated with the academic configuration of Dellenback equipped with a valve in the region of the sudden expansion [14]. The validation parameter is the radial variation $\frac{\mathrm{r}}{\mathrm{R}}$ of the ratio of $\frac{V_{\text {axial }}}{V_{\text {bulk }}}$ at axial position (x) of $20 \mathrm{~mm}$ as presented in Figure 4. The maximum error was less than $10 \%$, which represents a good agreement.

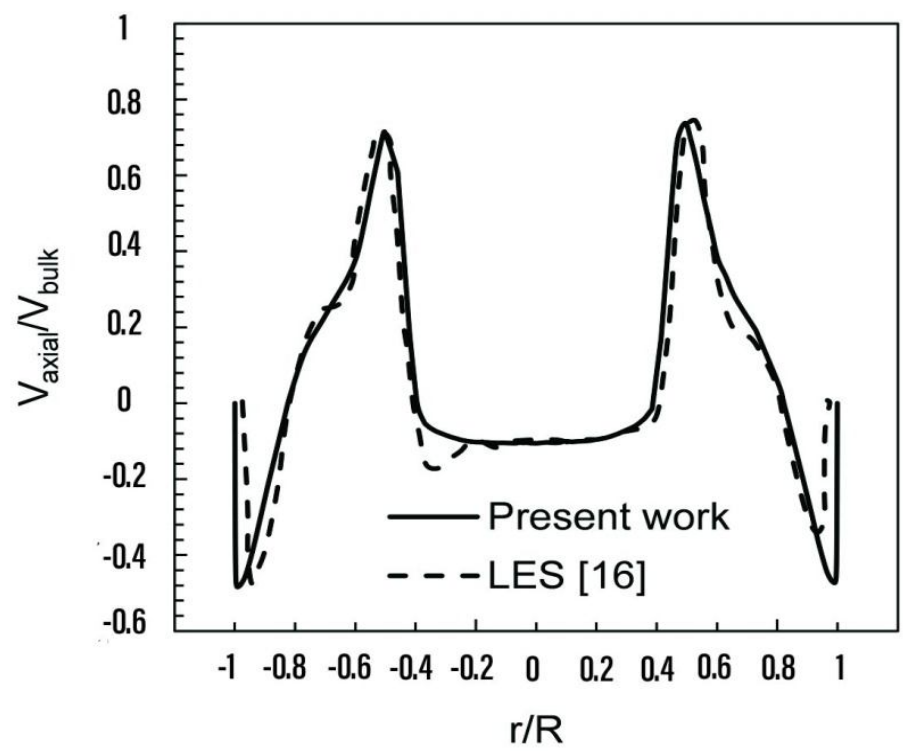

Figure 4 Model validation at $x=20 \mathrm{~mm}$

\section{Results and Discussion}

\section{Total pressure drop}

The total pressure drop change with the modification of the chamber crosssection during the breathing stroke was negligible. The ratio of the pressure drop of the WD $\left(\Delta \mathrm{P}_{\text {tot }}\right)$ to that of $\mathrm{CD}\left(\Delta \mathrm{P}_{\text {tote }}\right)$ was slightly higher than unity as presented in Figure 5 because the pressure drop in the breathing stroke occurs mainly in the breathing manifold and in the valve vicinity. At $\mathrm{N}=3000 \mathrm{rpm}$, the ratio was found to be less than 1.05 , which validates the previous information. 


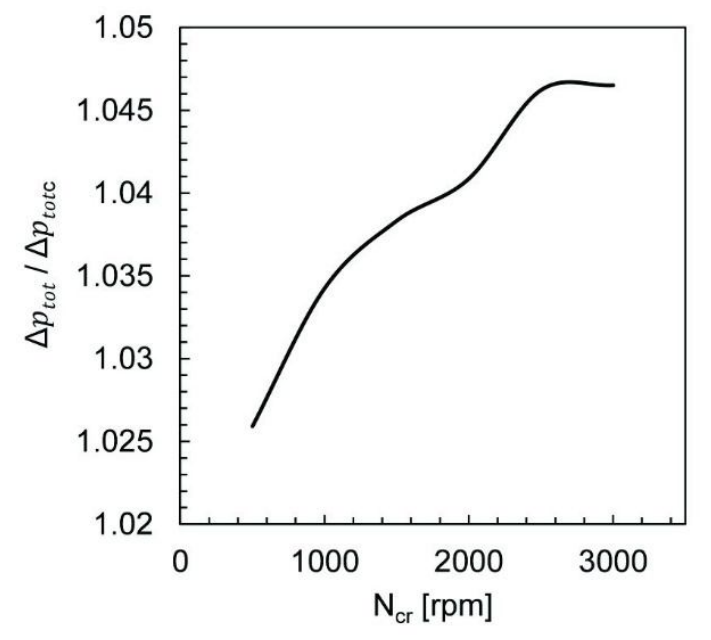

Figure 5 Pressure drop ratio of WD

\section{Vorticity and swirl number}

The topology of the vorticity in the normal direction of the two designs is represented in Figure 6. It's clear that CD has smoother contour lines with cores of farther distance from the wall. The fluid flow in the CD and the WD was different in locations depending on the wall impingement locations and the sudden expansions as shown in Figure 7 (a) and (b). Figure 7 (c) and (d) points out the differences in tumble motion between the two designs. The wedged design has higher values of tumble at the beginning, but $C D$ tumble motion retains longer. Figure 7 (e) and (f) illustrates the pattern and the intensity of the secondary flow at the outlet for both designs. The circular design showed higher values at more crosssectional area which is an indication for better mixing. Figure 8 (a) and (b) shows secondary vortex intensity behavior of the two designs which is different at locations of wall impingements. The behavior was different due to the differences between the wedged and circular designs in the geometry and in the hydraulic diameter with superiority in the circular design. The average values of $\mathrm{J}_{\mathrm{abs}}^{n}$ for $\mathrm{WD}$ and $\mathrm{CD}$ at $\mathrm{N}$ $=3000 \mathrm{rpm}$ were found to be $0.18 \mathrm{~s}^{-1}$ and $0.21 \mathrm{~s}^{-1}$ respectively.

Swirl number is another parameter to investigate vorticity behavior depending on the chamber axis as shown in Figure 8 (c) and (d). The average values of $\mathrm{S}$ for WD and $\mathrm{CD}$ at $\mathrm{N}=3000 \mathrm{rpm}$ were found to be 0.02 and 0.08 respectively. The comparison of $\mathrm{J}_{\mathrm{abs}}^{n}$ and $\mathrm{S}$ in Figure 8 (e) and (f) reveals that $\mathrm{CD}$ has higher values of $\mathrm{J}_{\mathrm{abs}}^{n}$ and $\mathrm{S}$ with better swirl decay behavior over WD. The axial variation of vortex parameters was smoother for $\mathrm{CD}$ than that of WD and decrease with the reduction of $\mathrm{N}$. The percentage reduction of $\mathrm{J}_{\mathrm{abs}}^{n}$ and $\mathrm{S}$ for WD compared to $\mathrm{CD}$ at $\mathrm{N}$ $=3000 \mathrm{rpm}$ were found to be $14.04 \%$ and $75.57 \%$, respectively. 

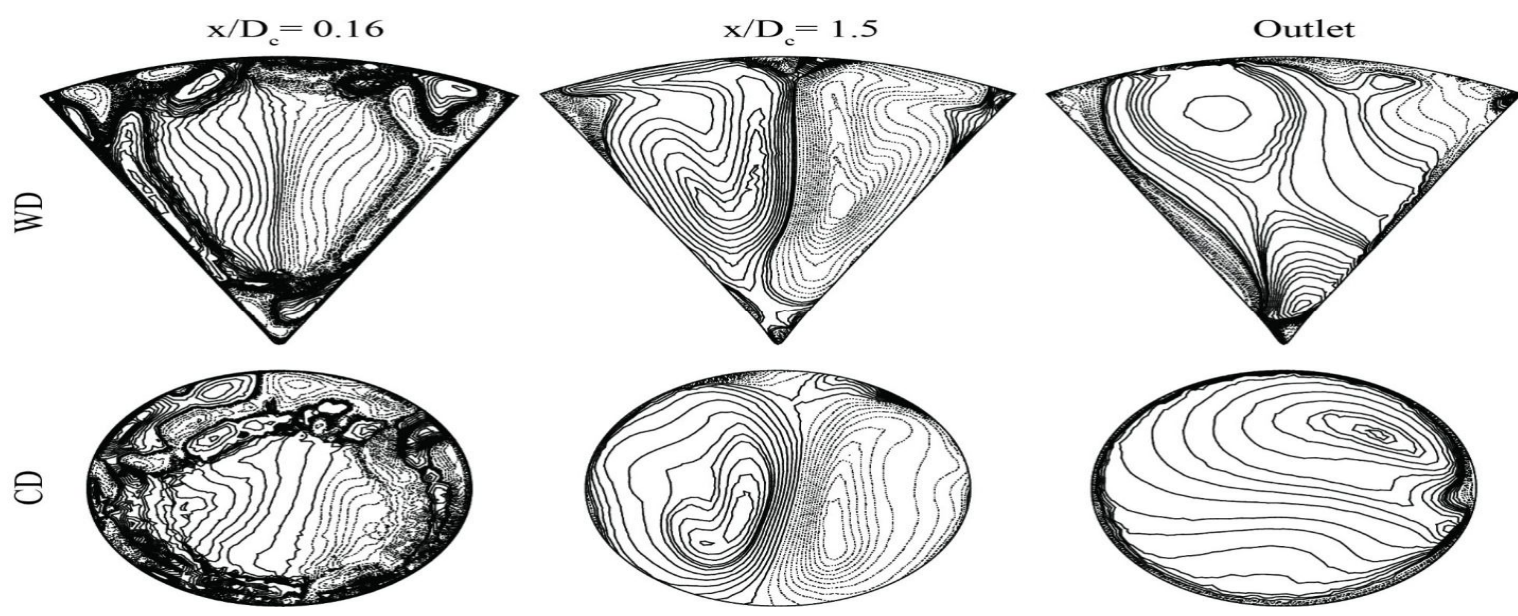

Figure $6 \mathrm{X}$-vorticity contour lines (dashed lines for negative values) at $\mathrm{N}=3000 \mathrm{rpm}$

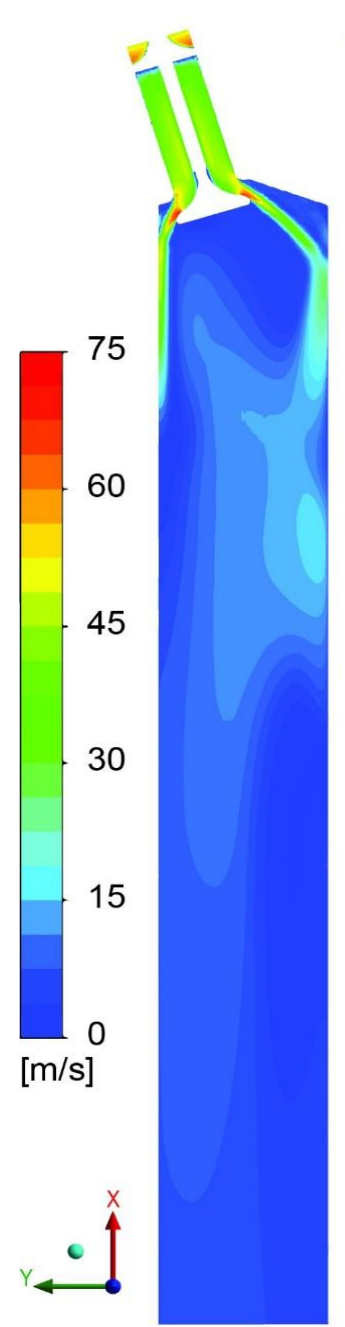

(a)

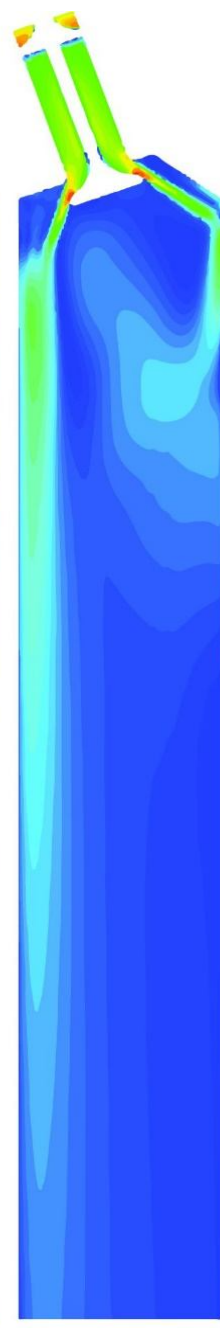

(b)
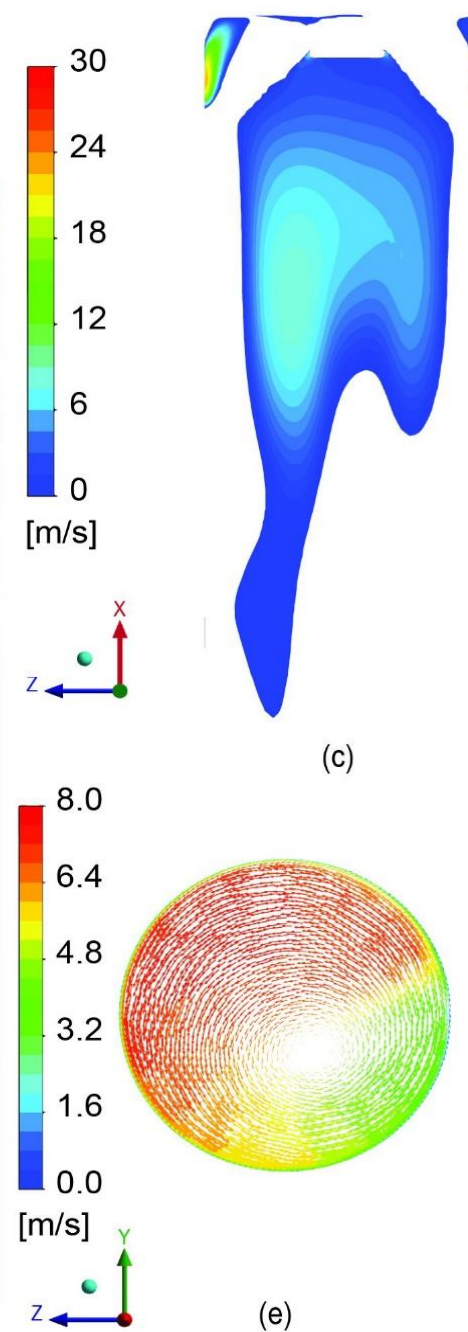

(c)
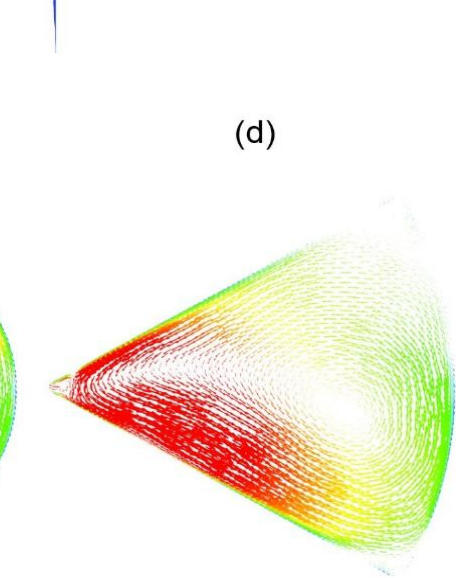

(e)

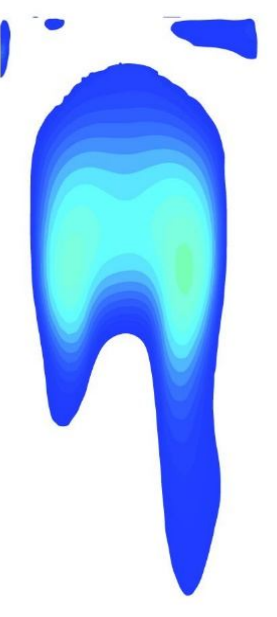

(d)

(f)

Figure 7 Velocity magnitude contours at $\mathrm{N}=3000 \mathrm{rpm}$ for (a) CD and (b) WD and Axial velocity contours in the upstream direction at $\mathrm{N}=3000 \mathrm{rpm}$ for (c) CD and (d) WD and Inplane vectors colored by velocity magnitude at $\mathrm{N}=3000 \mathrm{rpm}$ at outlet for (a) CD and (b) WD 


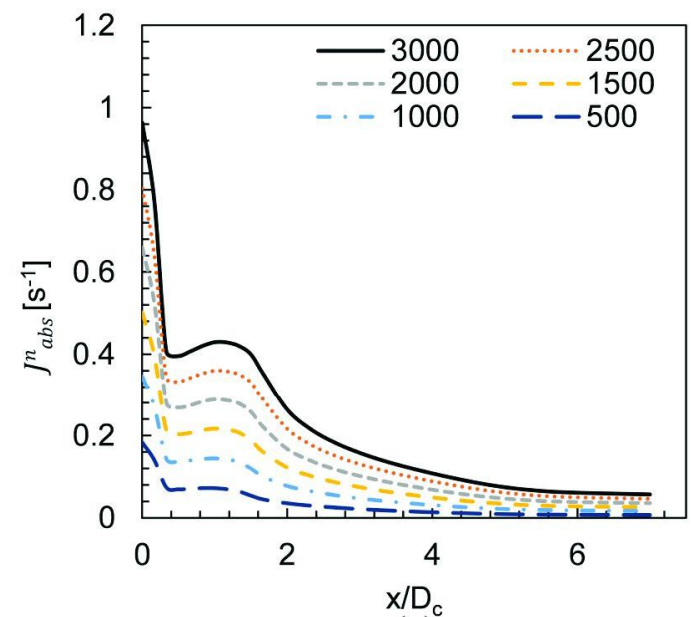

(a)

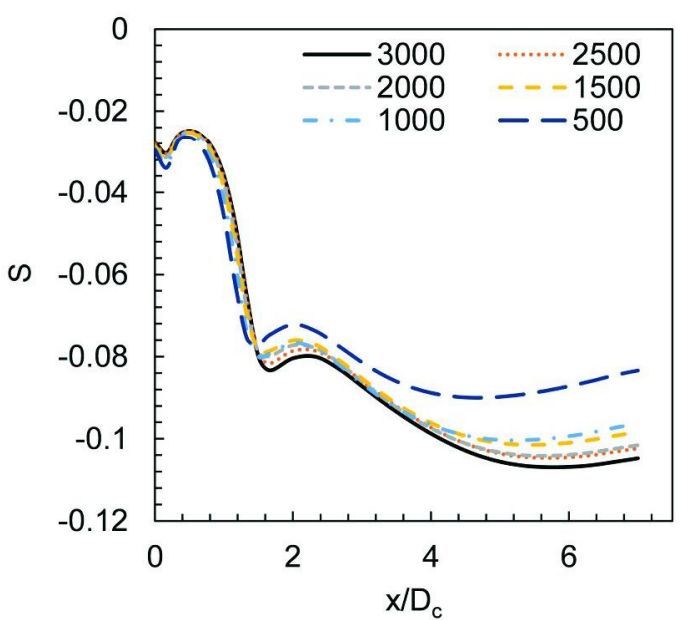

(c)

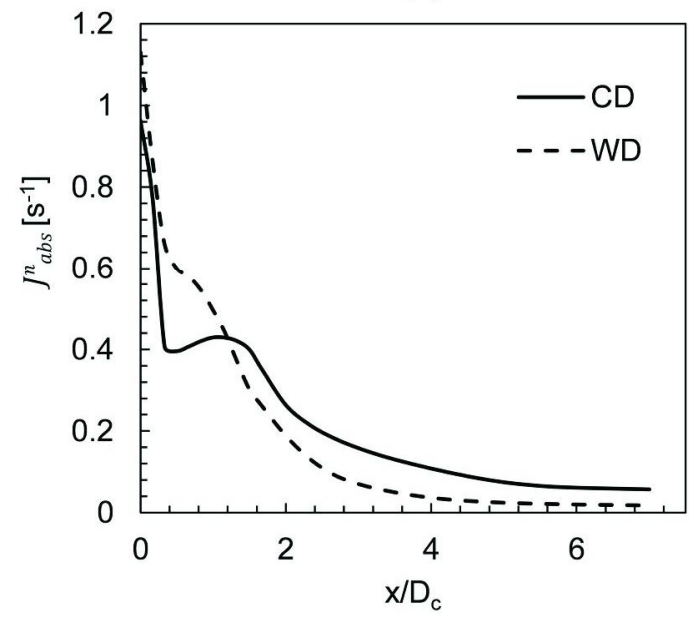

(e)

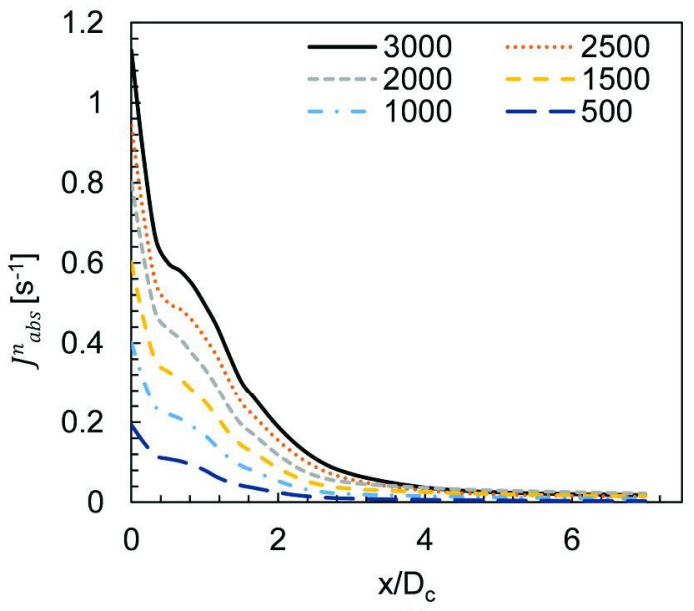

(b)

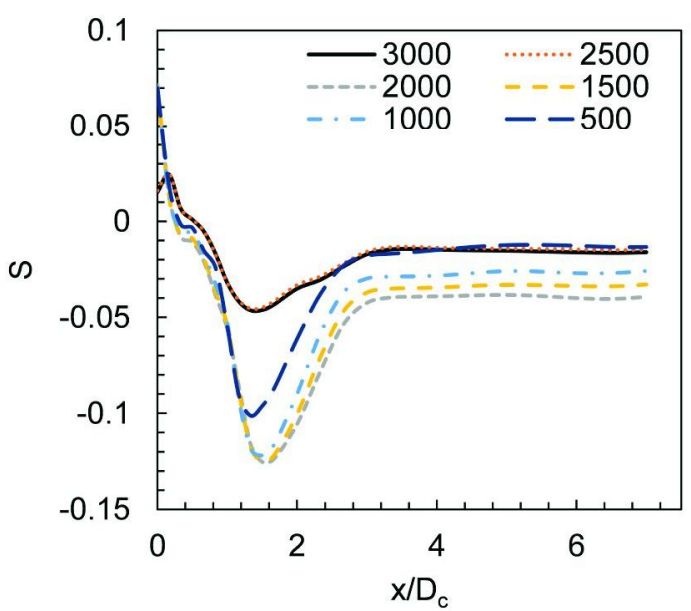

(d)

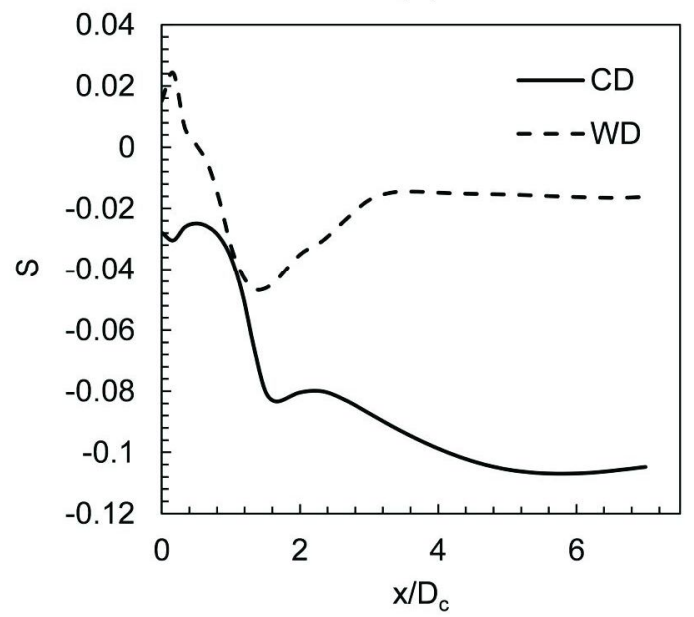

(f)

Figure $8 \mathrm{~J}^{\mathrm{n}}$ for (a) CD and (b) WD, $\mathrm{S}$ for (a) CD and (b) WD, and comparison of the two designs at $\mathrm{N}=3000 \mathrm{rpm}$ for (a) CD and (b) WD

\section{Conclusions}


Vol. 14, No. 2, May, 2021 ISSN: 2090-5890 \& 2735-3222

Future studies could be directed in the combustion characteristics and the transient analysis of different strokes to reveal the feasibility of the proposed design and increase compactness without sacrificing the performance characteristics.

\section{Reference}

[1] R.D. Reitz, H. Ogawa, R. Payri, T. Fansler, S. Kokjohn, Y. Moriyoshi, A.K. Agarwal, D. Arcoumanis, D. Assanis, C. Bae, K. Boulouchos, M. Canakci, S. Curran, I. Denbratt, M. Gavaises, M. Guenthner, C. Hasse, Z. Huang, T. Ishiyama, B. Johansson, T. V. Johnson, G. Kalghatgi, M. Koike, S.C. Kong, A. Leipertz, P. Miles, R. Novella, A. Onorati, M. Richter, S. Shuai, D. Siebers, W. Su, M. Trujillo, N. Uchida, B.M. Vaglieco, R.M. Wagner, H. Zhao, IJER editorial: The future of the internal combustion engine, Int. J. Engine Res. 21 (2020) 3-10.

https://doi.org/10.1177/146808741987 7990.

[2] J. Yin, A. Porporato, Diurnal cloud cycle biases in climate models, Nat. Commun. $8 \quad$ (2017) 2269. https://doi.org/10.1038/s41467-01702369-4.

[3] C. Hasse, Scale-resolving simulations in engine combustion process design
The wedge and circular crosssections of the combustion chamber are studied for the modeling of steady state flow during the breathing stroke. The results could reveal certain conclusions which could be listed as follows;

- The total pressure drop difference between the two designs across the compartment during the breathing stoke was negligible. As the pressure drop ratio of $\mathrm{WD}$ to $\mathrm{CD}$ was less than 1.05 at $\mathrm{N}=3000 \mathrm{rpm}$.

- The difference between mixing characteristics considering the secondary fluid flow parameters such as swirl number and vorticity was higher for the circular design. As the percentage reduction of $\mathrm{J}_{\mathrm{abs}}^{n}$ and $\mathrm{S}$ for WD compared to $\mathrm{CD}$ at $\mathrm{N}$ $=3000 \mathrm{rpm}$ were found to be $14.04 \%$ and $75.57 \%$, respectively.

- The wedged design presents a more compact design for the same displacement volume and reveals similar values associated with some performance characteristics. On the other hand, it exhibited lower values considering performance characteristics of the secondary flow. 
C, ASMEDC, 2008: pp. 819-827. https://doi.org/10.1115/IMECE200866490.

[10] Z. Abidin, K. Hoag, D. Mckee, N. Badain, Port Design for Charge Motion Improvement within the Cylinder, in: 2016. https://doi.org/10.4271/2016-01-0600.

[11] S. Pirozzoli, D. Modesti, P. Orlandi, F. Grasso, Turbulence and secondary motions in square duct flow, J. Fluid Mech. $840 \quad$ (2018) 631-655. https://doi.org/10.1017/jfm.2018.66.

[12] J. Qian, L. Ma, H. Zhan, Q. Luo, X. Wang, M. Wang, The effect of expansion ratio on the critical Reynolds number in single fracture flow with sudden expansion, Hydrol. Process. 30 (2016) 1718-1726. https://doi.org/10.1002/hyp.10745.

[13] D.N. Malkhede, H. Khalane, Maximizing Volumetric Efficiency of IC Engine through Intake Manifold Tuning, in: 2015. https://doi.org/10.4271/2015-01-1738.

[14] L. Thobois, G. Rymer, T. Soulères, T. Poinsot, Large-eddy simulation in IC engine geometries, SAE Tech. Pap. (2004). https://doi.org/10.4271/200401-1854.

[15] Varun, P. Singh, S.K. Tiwari, R. based on a systematic approach for model development, (2015). https://doi.org/10.1177/146808741559 7842.

[4] G. Kalghatgi, Is it really the end of internal combustion engines and petroleum in transport $\square$ ?, Appl. Energy. 225 (2018) 965-974. https://doi.org/10.1016/j.apenergy.201 8.05.076.

[5] Ganesan, INTERNAL COMBUSTION ENGINES, 4th ed., McGraw-Hill Education, 2012.

[6] J.B. Heywood, Internal Combustion Engine Fundamentals, 2nd ed., McGraw-Hill Education, 2018.

[7] R. Stone, Introduction to Internal Combustion Engines, 4th ed., SAE Intern. / Macmillan Press, 2012.

[8] A. Blechstein, K. Behnk, R. Deepe, S. Donath, A. Sommer, L. Stiegler, Effects of Charge Motion Characteristics on Engine Variables such as Emission Behavior and Efficiency, in: 2007. https://doi.org/10.4271/2007-01-0640.

[9] M. Mittal, H.J. Schock, R. Sadr, Evaluating the Influence of Charge Motion Control on In-Cylinder Flow Using MTV, in: Vol. 10 Heat Transf. Fluid Flows, Therm. Syst. Parts A, B, 
Whitelaw, Squish and Swirl-Squish Interaction in Motored Model Engines, J. Fluids Eng. 105 (1983) 105-112.

https://doi.org/10.1115/1.3240925.

[21] S. Bari, S.N. Hossain, I. Saad, A review on improving airflow characteristics inside the combustion chamber of CI engines to improve the performance with higher viscous biofuels, Fuel. 264 (2020) 116769. https://doi.org/10.1016/j.fuel.2019.11 6769.

[22] S. Bari, I. Saad, CFD modelling of the effect of guide vane swirl and tumble device to generate better in-cylinder air flow in a CI engine fuelled by biodiesel, Comput. Fluids. 84 (2013) 262-269.

https://doi.org/10.1016/j.compfluid.20 13.06.011.

[23] S. Bari, I. Saad, Effect of guide vane height on the performance and emissions of a compression ignition (CI) engine run with biodiesel through simulation and experiment, Appl. Energy. 136 (2014) 431-444. https://doi.org/10.1016/j.apenergy.201 4.09.051.

[24] S. Bari, I. Saad, Simulation and Experimental Investigation of Guide Vane Length to Improve the
Singh, N. Kumar, Modification in combustion chamber geometry of CI engines for suitability of biodiesel: A review, Renew. Sustain. Energy Rev. 79

1016-1033.

https://doi.org/10.1016/j.rser.2017.05. 116.

[16] J.F. Widmann, S.R. Charagundla, C. Presser, Characterization of the inlet combustion air in NIST's reference spray combustion facility:, Gaithersburg, $\quad$ MD, 2000. https://doi.org/10.6028/NIST.IR.6458.

[17] O. Lucca-Negro, T. O’Doherty, Vortex breakdown: a review, Prog. Energy Combust. Sci. 27 (2001) 431481. https://doi.org/10.1016/S03601285(00)00022-8.

[18] C.E. Morris, D.M. O'Doherty, A. Mason-Jones, T. O'Doherty, Evaluation of the swirl characteristics of a tidal stream turbine wake, Int. J. Mar. Energy. 14 (2016) 198-214. https://doi.org/10.1016/j.ijome.2015.0 8.001 .

[19] Á. Helgadóttir, S. Lalot, F. Beaubert, H. Pálsson, Mesh Twisting Technique for Swirl Induced Laminar Flow Used to Determine a Desired Blade Shape, Appl. Sci. $8 \quad$ (2018) 1865. https://doi.org/10.3390/app8101865.

[20] C. Arcoumanis, A.F. Bicen, J.H. 
[28] B.E. Launder, Second-moment closure: present... and future?, Int. J. Heat Fluid Flow. 10 (1989) 282-300. https://doi.org/10.1016/0142727X(89)90017-9.

[29] B.E. Launder, G.J. Reece, W. Rodi, Progress in the development of a Reynolds-stress turbulence closure, J. Fluid Mech. 68 (1975) 537-566. https://doi.org/10.1017/S0022112075 001814.

[30] F.R. Menter, Two-equation eddyviscosity turbulence models for engineering applications, AIAA J. 32 (1994) 1598-1605. https://doi.org/10.2514/3.12149.

[31] L. Tang, S. Yuan, M. Malin, S. Parameswaran, Secondary vortexbased analysis of flow characteristics and pressure drop in helically coiled pipe, Adv. Mech. Eng. 9 (2017) 168781401770005. https://doi.org/10.1177/168781401770 0059.
Performance of a Diesel Engine Run With Biodiesel, J. Eng. Gas Turbines Power. 138 (2016). https://doi.org/10.1115/1.4033509.

[25] S. Bari, I. Saad, Optimization of vane numbers through simulation and experiment, and investigation of the effect on the performance and emissions of a CI (compression ignition) engine run with biodiesel, Energy. 79 (2015) 248-263. https://doi.org/10.1016/j.energy.2014. 11.011 .

[26] S. WALlin, A. V. JOHANSSON, An explicit algebraic Reynolds stress model for incompressible and compressible turbulent flows, J. Fluid Mech. 403 (2000) 89-132. https://doi.org/10.1017/S0022112099 007004.

[27] M.M. Gibson, B.E. Launder, Ground effects on pressure fluctuations in the atmospheric boundary layer, J. Fluid Mech. $86 \quad$ (1978) 491-511. https://doi.org/10.1017/S0022112078 001251. 